14. Громова Е.М., Беркутова Д.И., Горшкова Т.А Подготовка современной молодежи к планированию профессиональной карьеры: монография. Ульяновск: УлГПУ, 2013. 170 с.

15. Громова Е.М., Беркутова Д.И., Горшкова Т.А. Ценности личности как основа жизненной и профессиональной стратегии // Современные проблемы науки и образования. 2013. № 2. С. 315.

16. Мескон М., Альберт М., Хедоури Ф. Основы менеджмента. 3-е изд. / Пер. с англ. М.: ООО «И.Д. Вильямс», 2006. 672 с.

17. Почебут Л.Г., Чикер В.А. Организационная социальная психология: учеб. пособие. СПб.: Изд-во «Речь», 2002. 298 с.
18. Ильин Е.П. Дифференциальная психология профессиональной деятельности. СПб.: Питер, 2008. $432 \mathrm{c}$.

19. Климов Е.А. Психология профессионального самоопределения: учеб. пособие для вузов. М.: Академия, 2004. 302 с.

20. Румянцева Т.В. Психологическое консультирование: диагностика отношений в паре. СПб.: Речь, 2006. $176 \mathrm{c}$.

Статья публикуется при поддержке гранта РФФИ № 19-013-00184 "Становление профессиональной идентичности как фактор проектирования карьерной стратегии современного профессионала».

\title{
VALUABLE ASPECTS OF PROSPECTIVE TEACHER'S PROFESSIONAL IDENTITY DEVELOPMENT
} (C) 2019

Berkutova Diana Iskanderovna, candidate of pedagogical sciences, associate professor of Mathematical Methods and Technological Education Department

Gromova Ekaterina Mikhailovna, candidate of pedagogical sciences, associate professor of Mathematical Methods and Technological Education Department

Gorshkova Tatyana Anatolyevna, candidate of pedagogical sciences, associate professor of Mathematical Methods and Technological Education Department Ulyanovsk State Pedagogical University (Ulyanovsk, Russian Federation)

Abstract. The paper actualizes one of the most important problems of modern higher education - prospective teacher's professional identity development. The authors study the history of the problem of identity, analyze the main theoretical approaches to the essence of the concept from the point of view of foreign and domestic scientists, and provide options for planning horizontal and vertical career of the teacher. The paper presents the results of the study of pedagogical university students' value orientations in the context of planning their career strategy. The experimental sample of respondents consisted of full-time students of Physical, Mathematical and Technological Education Department of the Ulyanovsk State Pedagogical University named after I.N. Ulyanov. They were diagnosed by F. Herzberg's method, aimed at identifying the predominant role of hygienic factors or motivators in the career, as well as by Edgar H. Schein's «Career Anchors» method, used to determine the leading professional motives. The results of the study were subjected to a thorough analysis. The paper presents comparative data of the diagnostics. The obtained materials can serve as a starting point for further theoretical and practical development of the problem of successful prospective teacher's professional identity development.

Keywords: identity; social identity; professional identity; horizontal career; vertical career; personal values; young teacher; F. Herzberg's method; Edgar H. Schein's «Career Anchors» method; E.A. Klimov's «Differential and diagnostic questionnaire» method; M. Kuhn's questionnaire «Who am I?».

$* * *$

УДК 378.147

\section{ОПТИМИЗАЦИЯ ПРОЦЕССА ФОРМИРОВАНИЯ ПРОФЕССИОНАЛЬНЫХ ИНОЯЗЫЧНЫХ РЕЧЕВЫХ КОМПЕТЕНТНОСТЕЙ СТУДЕНТОВ ПРОФИЛЯ «ТУРИСТСКИЙ БИЗНЕС» В ЭКОНОМИЧЕСКОМ ВУЗЕ}

(C) 2019

Глухов Геннадий Васильевич, доктор педагогических наук, профессор, заведующий кафедрой лингвистики и иноязычной деловой коммуникации

Ермакова Юлия Дмитриевна, кандидат педагогических наук, доцент кафедры лингвистики и иноязычной деловой коммуникации Капустина Любовь Викторовна, кандидат педагогических наук, доцент кафедры лингвистики и иноязычной деловой коммуникации Самарский государственный экономический университет (2. Самара, Российская Федерация)

\footnotetext{
Аннотация. В данной статье рассматриваются способы оптимизации процесса формирования профессиональных иноязычных компетентностей студентов неязыкового вуза на примере организации языковой и речевой подготовки студентов экономического вуза по профилю «Туристский бизнес», которая сочетает в себе комплексное бизнес-обучение с предпринимательским подходом будущих квалифицированных специалистов для работы в индустрии отдыха и туризма. Это предполагает овладение студентами необходимыми компетентностями, нацеливающими их на перспективу стать предпринимателями и менеджерами, способными реализовать свой рабочий потенциал как на региональном, так и на международном уровне. Это, в свою очередь,
} 
предъявляет достаточно высокие требования к профессиональной языковой подготовке в неязыковом вузе и подразумевает свободное владение иностранным языком выпускниками данного профиля. Дополнительным катализатором для Самарской области и десятка других регионов Российской Федерации стал прошедший в 2018 году чемпионат мира по футболу, стимулирующий формирование современной инфраструктуры отрасли туризма и подтвердивший необходимость и актуальность изменений в области высшего профессионального образования. Глобализация и интернет изменили все аспекты иноязычной подготовки, в том числе и в неязыковом вузе, особенно для направлений и профилей подготовки индустрии туризма и гостиничного бизнеса. Многие стратегии, применяемые в системе высшего образования до недавнего времени, уже не являются эффективными в настоящее время из-за новых постоянно появляющихся и обновляющихся технических возможностей.

Ключевые слова: профессиональная языковая подготовка; туристский бизнес; формирование профессиональных иноязычных компетентностей студентов; эффективные стратегии в овладении иностранным языком; английский язык в сфере профессионального общения; языковые и речевые компетентности; неязыковой вуз.

\section{Введение}

Организации, занимающиеся туристским бизнесом, учатся быстро реагировать на изменение потребительских и деловых тенденций, связанных с тем, где потенциальные клиенты ищут информацию и бронируют свои поездки. Это крайне необходимо, чтобы поддерживать и успешно развивать свой бизнес. Компании в этой отрасли чаще, чем другие, осознают необходимость различных каналов коммуникации, которые могут использоваться с целью привлечь конкретные региональные туристические рынки и рассматриваются как традиционные, так и инновационные каналы коммуникации: печать, СМИ, интернет, агентства и компании по бронированию, а также «сарафанное» радио. Умение определить, что эффективно и неэффективно сейчас и будет в ближайшем будущем на основе конкретных тенденций, которые в настоящее время влияют на эволюцию отрасли - от планирования и бронирования до опыта прибытия в пункт назначения и поездки домой, гарантирует выпускнику профиля «Туристский бизнес» успешную самореализацию в профессиональной деятельности после завершения обучения [1]. В свою очередь, это зависит не только от реализуемых методов маркетинговых стратегий и способов управления человеческими ресурсами, но и от уровня языковых компетентностей специалистов этой индустрии, что напрямую зависит от внедряемой системы высшего образования в нашей стране.

Иностранный язык изначально воспринимается как неотьемлемая часть профессиональной деятельности в сфере туризма и всецело влияет на эффективность подготовки специалистов для данного профиля профессиональной подготовки, что с недавних пор стало особенно актуально для региона Самарской области. После проведения чемпионата мира по футболу в 2018 году многие пришли к пониманию того, что навыки иностранного языка могут быть широко использованы в туристском бизнесе не только в популярных курортных и давно зарекомендовавших экскурсионных направлениях Российской Федерации, таких как Сочи, Москва, Санкт-Петербург, но и менее крупных городах Поволжского региона, каким является г.о. Самара. Ситуация действительно кардинально изменилась каких-то пару лет назад. Обширная вновь возведенная инфраструктура города позволяет принимать мероприятия мирового уровня и привлекает большое количество иностранных туристов. Сегодня вряд ли кто сомневается в актуальности и первостепенной государственной важности в реализации новых образовательных стратегий, отвечающих потребностям быстро изменяющегося рынка, а санкционные войны и колебания курсов валют лишь обострили очевидность необходимого развития отечественной туриндустрии [2].
Как и любая другая отрасль, индустрия туризма и отдыха также должна адаптироваться к изменениям, вызванным текущими процессами оцифровки. На этом фоне исследования туристского бизнеса направлены на подготовку специалистов, способных к нестандартному мышлению. Плохие знания иностранного языка, в частности английского, очевидно являются результатом ограниченной практики. Преподавание английского языка требует организации процесса обучения, «синергируя» все возможные ресурсы, богатство которых ещё трудно было себе представить несколько лет назад. Бесчисленное многообразие вебинаров, on-line обучающих программ, интерактивных ресурсов позволяет обеспечить достаточно времени для практики речи, несмотря на неоправданно и неудержимо сокращающееся количество аудиторных часов по иностранному языку в неязыковом вузе.

Как и ранее, владение иностранным языком в сфере туризма воспринималось работодателями как объективная необходимость будущего кандидата, но чаще всего выпускники со знанием языка этого профиля пытались найти место работы за пределами региона, а иногда и страны, и тогда иностранный язык, в большинстве случаев это английский язык, являлся единственным связующим звеном, чтобы общаться с иностранными англоязычными и неанглоязычными сотрудниками и работать по всему миру, в том числе в неанглоязычных странах.

Иностранный язык в индустрии туристского бизнеса необходим для оказания широкого спектра услуг иностранным путешественникам, где всё нацелено на предоставление квалифицированного обслуживания для достижения удовлетворенности клиентов. Клиенты чаще всего ищут исключительный и индивидуальный подход в сервисе, который бы реализовывался быстро и качественно. Услуга made-tomeasure обычно исходит из организационных вопросов, к которым привыкли клиенты, начиная с таких, как любимый напиток гостей, предпочитаемый тип номера, и заканчивая свободным владением разговорным английским языком персоналом [3]. Многие туристы, которые путешествуют довольно часто, не могут преуспеть в изучении языка другой страны, куда они отправляются, и тогда большинство их них вспоминает о признанном лидере среди международных языков общения - английском. Поэтому условие наличия в отеле англоговорящего персонала уже не воспринимается как каприз или как что-то из ряда вон выходящее, а кажется вполне оправданным. Если принимающая сторона, например отель, в котором остановился клиент, не в состоянии предоставить качественное обслуживание из-за того, что сотрудники не могут гарантировать корректное использование иностранного языка по его прямому утилитарному назначению, т.е. реализовать акт положительной коммуникации в рамках 
простых бытовых или узкопрофессиональных тематик, что достаточно часто имеет место быть, неизбежна ситуация, когда у клиента складывается негативное мнение по отношении к этому конкретному отелю или ресторану, городу, а иногда и стране. Поэтому в индустрии туризма обычно стараются идти навстречу предпочтениям клиента, обеспечив многоязычное обслуживание, для того чтобы поддержать потребности клиентов.

\section{Анализ последних исследований и публикаций}

Английский язык является наиболее распространенным языком во всем мире и всецело связан с подготовкой студентов по профилю «Туристский бизнес». Большое число не англоговорящих сотрудников в отелях региона вызвало множество проблем в гостиничных компаниях, которые зачастую связаны с повседневным общением на уровне работник - клиент. Стало очевидно, что с этой проблемой больше нельзя мириться, так как это негативно сказывается на функционировании многих компаний и на престиже региона.

Исследование, проведенное по такой же проблематике, journal of hospitality \& tourism research, показало, что 53,5\% гостиничных предприятий сообщили, что «высшее руководство обратило внимание на языковые барьеры на рабочем месте». В самом деле, $46,5 \%$ заявили, что их компания помогает сотрудникам с ограниченными языковыми компетентностями улучшить их профессиональные навыки, предлагая курсы повышения уровня владения английским языком на рабочих местах по широкому спектру программ без отрыва от производства. Большинство констатирует факт крайней необходимости таких курсов. Согласно опросу, отмечается, что «32\% компаний предоставляют языковую подготовку для сотрудников, чтобы те приобрели язык для специальных целей, и 52\% сотрудников ожидают, что языковой курс будет коммуникативным с профессиональными тематиками» [3]. Очевидно, это показывает, что есть спрос в применении иностранного языка на практике в профессиональных ситуациях. Сотрудники стремятся свободно общаться со своим высшим руководством, чтобы выполнять правильную задачу, находясь на рабочем месте. Работодатели также ожидают высоких результатов в предоставлении обслуживания по самым высоким стандартам, что напрямую связано с репутацией компании.

Преодоление языковых барьеров, блокирующих путь к успеху в туристском бизнесе, - основная цель языковой подготовки студентов неязыковых направлений подготовки и профилей, в особенности профиля «Туристский бизнес», который является необходимой частью программы профессионально-ориентированного образования. Кроме того, углубленные языковые тренинги помогают развить позитивное профессиональное отношение, которое способствует позитивному влиянию на работу в команде. Выпускники экономического университета, по профилю «Туристский бизнес», свободно владеющие разговорным английским, имеют значительные преимущества при устройстве на работу, и иностранный язык становится решающим для образования в этой отрасли.

Цель исследования: теоретико-методологическое обоснование и экспериментальная проверка оптимальных стратегий формирования иноязычных речевых компетентностей профессиональной подготовки студентов профиля «Туристский бизнес» в экономическом вузе.
Объект исследования: процесс формирования иноязычных речевых компетентностей в рамках профессиональной подготовки студентов профиля «Туристский бизнес» в экономическом вузе.

Предмет исследования: оптимальные стратегии формирования иноязычных речевых компетентностей профессионально-ориентированной направленности студентов профиля «Туристский бизнес» в экономическом вузе.

\section{Материалы и методика исследования}

Методологическую основу составили: личностноориентированный подход (И.Л. Бим, М.Л. Вайсбурд, Н.В. Витг, М. Уайт и др.); коммуникативный метод в обучении иностранным языкам (И.А. Зимняя, Г.А. Китайгородская, Я.М. Колкер), интерактивное изучение иностранных языков, которое рассматривается как направление, реализующееся в различных методических системах (Л.Ш. Гегечкори, И.Ю. Шехтер, В.В. Петрусинский, Г.А. Китайгородская, К. Madlener, Granger, Sylviane, Gaëtanelle Gilquin, Fanny Meunier A.A. Леонтьев, Е.И. Пассов, S. Granger, G. Gilquin, F. Meunier, внедрение интерактивных методов в обучение языкам (И.И. Борисова, Е.Ю. Ливанова, Т. Cobb, M. Horst), исследования в работах таких зарубежных авторов, как A. Yudintseva, M. Juma, R. Guy \& G. Marquis, R. Van Eck, S. Wallden \& A. Soronen, T. Millington Neil [4].

Теоретическую основу составили положения актуальных аспектов лигвистики и дидактики (Н.Д. Гальскова, Р.П. Мильруд); работы, направленные на изучение активизации процесса обучения в вузе (Ю.К. Бабанский, В.В. Карпов, А.Л. Назаренко, М. Уайт, М.А. Ярмашевич и др.); положения в ходе реализации профессиональной подготовки по иностранному языку (И.С. Башмакова, А.В. Конышева, Т.С. Серова, Г.В. Глухов, Ю.Д. Ермакова, Л.В. Капустина и др.), а также идеи по внедрению современных технологических возможностей в преподавание иностранных языков в вузе (Е.С. Полат, Е.Н. Соловова, Т.И. Шаталова, А.Н. Щукин, П.А. Юцявичене и др.) [4].

Методами исследования послужили российские и зарубежные источники по данной проблематике; изучение теоретико-методологических и психологопедагогических аспектов преподавания иностранных языков, регламентирующих документов Министерства образования. А также использовались такие методы проведения эксперимента, как: тестирование, опрос, мониторинг и обработка полученных результатов.

\section{Результаты исследования и их обсуждение}

Исследование проводилось на базе Самарского государственного экономического университета с 2017-2019 гг. со студентами профиля «Туристский бизнес». Эксперимент проводился в 3 этапа: 1-й этап - разработка обшей концепции реализации выбранных стратегий по оптимизации процесса формирования иноязычных речевых компетентностей профессионально-ориентированной направленности студентов профиля «Туристский бизнес» в экономическом вузе; 2-й - собственно сам эксперимент, включающий подбор студентов для экспериментальной и контрольных групп, подготовка и проведение аудиторных занятий, мониторинг и контроль учебной деятельности студентов, участвующих в эксперименте, проведение текущих, итоговых тестирований, сбор результатов; 3-й этап - обработка всей отчетной документации по проводимой экспериментальной части исследования, выводы по полученным результатам. 
Многолетний педагогический опыт показывает, что ежегодно только $20 \%$ выпускников данного профиля свободно владеют английским языком. В первую очередь - это следствие недостаточного количества аудиторного времени для индивидуальной разговорной практики под руководством преподавателя, выделяемое на изучение английского языка: на данный момент всего шесть часов в 2 недели для студентов группой из 15-18 человек. Катастрофическая нехватка учебного времени, которое может быть отведено на разговорную практику, делает студентов неуверенными в общении на английском языке даже со своими одногруппниками, не говоря уже о незнакомых людях, особенно иностранцах. Это серьезная проблема для выпускников, учитывая, что их работа будет включать потенциально ежедневное использование иностранного языка.

В преподавании английского языка как средства коммуникации преподавателю отводится центральная роль, т.к. преподавание английского языка как средства коммуникации призвано научить учащихся понимать и взаимодействовать друг с другом как в устной, так и в письменной форме. Обучение - это процесс, предоставляющий студентам возможность реализовать опыт творческого осмысления. Это означает, что обучение предназначено не только для того, чтобы студенты научились понимать иноязычную речь, но, что более важно, также для предоставления им возможностей использовать приобретенный лексико-грамматический багаж в реальных коммуникативных ситуациях. Именно поэтому обучение должно вовлекать студентов в смоделированную преподавателям наиболее оптимальную для каждой конкретной группы деятельность по использованию того материала, что они изучают. В наше время это достаточно просто реализовать, используя учебные ресурсы в интернете. Задача преподавателя правильно подобрать ссылки, сайты, видео- и аудиоматериалы, выложенные в большинстве своем в открытом бесплатном доступе в сети, и направить студентов, мотивируя их на конечный результат [5; 6].

В большей степени, чем другие отрасли, туризм является «информационно-интенсивной» отраслью, которая состоит из многочисленных компонентов, которые должны слаженно работать вместе. По сути, это была одна из первых отраслей, которая широко приняла многие из появляющихся каналов связи, которые увеличили интерактивность внутри индустрии. С появлением интернет-ресурсов появился не только относительно недорогой канал доставки информации, но и способный реализовать маркетинговые и коммуникационные функции удаленного доступа, периферийные и островные направления, которые получают возможность напрямую общаться со своими потенциальными клиентами и дифференцировать свой продукт в соответствии с их потребностями. Традиционные каналы связи не могли обеспечить такой географический охват, который предоставляет интернет, создавая инфраструктуры с безграничной информационной конвергенцией. Игнорировать это в обучении иностранному языку в неязыковом вузе означало бы изолировать будущих профессионалов от уникальных возможностей оптимизировать и ускорить процесс овладения ими необходимыми профессиональными и языковыми навыками.

Говорение считается одним из самых сложных навыков в изучении английского языка. Как один из рецептивных навыков, говорение является основой для развития других языковых навыков. В течение длительного периода времени преподавание английского языка в основном было сосредоточено на обучении чтению и письму на ранней стадии обучения и пренебрегало обучением аудированию и говорению. Многие преподаватели в своей практике сталкиваются с ситуацией, когда студенты получают хорошую оценку в тесте по английскому языку, но далеко не все из них могут хорошо воспринимать иноязычную речь и беспрепятственно порождать высказывание. Поскольку основная функция языка - это взаимодействие и коммуникация, совершенствование устной коммуникативной компетенции студентов профиля «Туристский бизнес» является особенно важной проблемой. Очевидно, что обучающимся неязыкового вуза не хватает и эффективной практики аудирования, и говорения на продвинутом уровне. Результаты эксперимента, реализуемого в течение 2 лет со студентами профиля «Туристский бизнес» (2 года с контрольной группой и 1 год с экспериментальной), подтверждают, что ключевыми стратегиями выступают [6; 7]:

- когнитивные стратегии - это поведение и мыслительные операции, осуществляемые обучаемым для кодификации иностранного языка. Это его манера отбирать, приобретать, организовывать и интегрировать новые знания;

- метакогнитивные стратегии, относящиеся к области планирования и контроля, который осуществляется человеком над его собственным обучением. Внутри них организованы когнитивные стратегии техники, которые непосредственно используются обучаемым;

- аффективные стратегии, характеризующие эмоциональные реакции при попытках решения учебной задачи;

- социальные стратегии, касающиеся взаимоотношений между изучающим иностранный язык и теми, кто вместе с ним его изучает. На практике часто социальные и аффективные стратегии образуют единые социо-аффективные стратегии, так как языковое общение в социальной группе неизбежно сопровождается эмоциями;

- компенсаторные стратегии - это приемы, позволяющие преодолеть дефицит языковых средств или недостаточное развитие речевых умений $[6 ; 7]$.

В последние десятилетия был достигнут значительный прогресс в преподавании английского языка, но есть еще некоторые проблемы, которые все еще вызывают обеспокоенность. Основная из них заключается в том, что, несмотря на последовательную практику и подчас изнурительную работу, многие студенты не могут правильно использовать английский язык после 2-х лет преемственного обучения в вузе, особенно устный английский оставляет желать лучшего почти у $80 \%$ обучающихся. Причину этого, кроме мизерного количества аудиторных часов, выделяемых на дисциплину «Иностранный язык» в неязыковом вузе, мы видим еще и в том, что по-прежнему используются старые, пассивные методы обучения иностранному языку.

Полученные результаты эксперимента демонстрируют значительный прирост речевой и языковой активности студентов в экспериментальной группе, где студентам предлагался в качестве домашнего задания, а иногда и просто дополнительного материала для ознакомления, подобранный в соответствии с тематикой учебного плана материал из интернет- 
источников, по сравнению с контрольной группой, где использовался один учебник, заявленный как обязательный согласно требованиям УМО, и положительная динамика изменений была гораздо ниже. Так, на момент начала эксперимента у студентов контрольной группы было незначительное преимущество по уровню языковых и речевых компетентностей, что составило около $3 \%$ (59\% и 62\%), но уже через один учебный семестр показатели экспериментальной группы сравнялись, даже немного опередили результаты контрольной группы и составили 69\% и $67 \%$ соответственно. К концу первого семестра 2 го курса, когда дисциплины «Иностранный язык» и «Деловой иностранный язык» заканчивают языковую подготовку студентов рассматриваемого профиля, данные заключительных тестирований подтвердили эффективность использования дополнительных интерактивных интернет-ресурсов.

Академическая успеваемость участвующих в эксперименте студентов подтверждена результатами тестовых предварительных исследований. После участия в данной программе студенты добились значительных успехов в разговорном английском языке, о чем свидетельствуют их результаты итогового теста (79\% - экспериментальная группа, 73\% - контрольная). Сделан вывод о том, что применение современных ресурсов гарантирует эффективность в повышении разговорной и языковых компетентностей студентов профиля «Туристский бизнес» в неязыковом вузе.

\section{Обсуждение}

В процессе обучения иностранному языку в неязыковом вузе преподаватель часто сталкивается со студентами, чей уровень владения иностранным языком можно отнести к закрепившемуся понятию «false beginners», т.е. с теми, кто изучал иностранный язык, но этот опыт был не совсем успешным. Поэтому приходится заново объяснять базовые фундаментальные основы устройства языка, чтобы студенты знали и понимали грамматические правила, могли читать транскрипции, а только потом уже приступать к отработке разговорной лексики по общим и профессиональным темам, таким как знакомство, представление кого-то, телефонный разговор, типичные бытовые вопросы, благодарность, извинение, приглашение, приветствие, передача сообщения, прощание и т.д. Благодаря этому речь становится продуктивным навыком, который требует от учащихся спонтанного порождения высказывания, используя имеющийся словарный лексико-грамматический запас, который будет давать возможность выражать посредством иностранного языка то, что они хотят передать в неожиданных, неподготовленных речевых ситуациях [8; 9]. Неподготовленное речевое высказывание, реакция представляет собой сложный процесс, который включает в себя лингвистические аспекты, такие как способность произносить правильные звуки, использовать правильную грамматику, а также необходимость обладать достаточно обширным вокабуляром, находящимся в зоне активного использования, чтобы за короткий промежуток времени суметь подобрать адекватную лексику для данной конкретной ситуации. Делая акцент на развитии речевых навыков, важно помнить, что изучение языка - это не то же самое, что обучение языку. Две важные вещи в изучении английского языка выходят на передний план - это индивидуальная заинтересованность и ежедневная практика. Это означает, что практика в той или иной форме проводится каждый день, и каждый участник пытается найти эту практику самостоятельно, индивидуально или с подачи преподавателя. Такая работа, конечно, предполагает кураторство со стороны того же преподавателя, помощь в подборе материалов, иногда проверке и контроле, но основой всему служит личная заинтересованной студентов. Высшая школа это не среднее образование, которое должен получить каждый. Здесь включается другой механизм познания образования, студент должен научиться доставать необходимые ему знания, и сейчас, как никогда, у него для этого есть все условия и ресурсы.

«Язык - это дорожная карта культуры. Он говорит вам, откуда пришли его люди и куда идут» (Рита Мей Браун) [7]. Язык - это не нереальный объект, который можно только изучать, но это реальная вещь, поскольку она используется людьми каждый день. Он играет важную роль в жизни человека, так как является средством общения между людьми. В эпоху глобализации английский язык как основное средство коммуникации должен активно осваиваться как в письменной, так и в устной форме. Как один из самых важных мировых языков, английский язык предназначен не только для академических нужд студентов, преподавателей или исследователей, но и для ищущих работу, рабочих, деловых людей, предпринимателей, государственных служащих и членов общества [10-12]. В рамках государственного экономического университета студенты профиля «Туристский бизнес» имеют большую, по сравнению со студентами других профилей неязыкового вуза, мотивацию к овладению иностранным языком, а именно не только ради хороших оценок по предмету, но и для того, чтобы иметь надежные коммуникативные навыки, чтобы в дальнейшем получить более привлекательные предложения на работу.

\section{Выводы исследования \\ и перспективы дальнейших изысканий данного направления}

Преподавание иностранных языков для студентов профиля «Туристский бизнес» было сосредоточено на изучении профессиональных целей, с которыми студенты, вероятно, столкнутся в своей будущей карьере. В результате активного использования дополнительных интернет-источников отмечается приобретение общепрофессиональных компетентностей студентами туристского бизнеса, таких как: развитие кросс-культурных представлений, составление наиболее привлекательной экскурсионной карты для туристов в своем регионе, овладение нормами делового этикета и ведения деловой переписки и др., что готовит их к реальным ситуациям использования иностранного языка в будущей профессии в сфере туризма.

По мере того как количество международных туристов увеличивается по всему миру, одновременно увеличивается потребность в найме сотрудников, свободно владеющих иностранным языком. В этой связи уровень владения иностранным языком всегда оказывал значительное влияние на показатели эффективной работы. Языковые барьеры в основном наблюдаются во время бытового, повседневного речевого общения и в рамках сугубо профессиональных тематик коммуникативных ситуаций.

Иностранный язык всегда оказывал большое влияние на туристическую индустрию в целом. Но за последние несколько лет все большее количество сотрудников отелей, менеджеров и студентов, проходящих обучение по профилю «Туристский бизнес», 
осознали важность владения вторым иностранным языком на продвинутом уровне. Это подчеркнутое профессиональное отношение к изучению иностранного языка в основном связано с тем, что навыки иностранного языка могут быть использованы в отрасли для различных целей. В конечном счете, высокий уровень владения иностранным языком приводит к большой отдаче, оказывающей положительное влияние как на личностное развитие студентов, так и на их профессиональный рост.

\section{Список литературы:}

1. Пирогова О.В. Перспективы развития туристского образования // Современные проблемы науки и образования. 2016. № 6. С. 375 .

2. Туризм как фактор регионального развития: мат-лы VIII междунар. науч.-практ. конф. (Екатеринбург, 20 апреля 2018 г.). Екатеринбург: Изд-во УрГЭУ, 2018. 134 с.

3. Meurers D., Dickinson M. Evidence and Interpretation in Language Learning Research: Opportunities for Collaboration with Computational Linguistics // Language Learning. 2017. Vol. 67 (S1). P. 66-95.

4. Глухов Г.В., Ермакова Ю.Д., К Капустина Л.В. Новые тенденции в преподавании иностранных языков // Вестник Самарского государственного технического университета. Серия: Физико-математические науки. 2018. № 2. С. 37-51.

5. Данилина Е.А. Обучение студентов вуза английскому языку на основе компетентностно-модульной организации учебного процесса (направление подготовки «Туризм», бакалавриат): дис. ... канд. пед. наук. Нижний Новгород, 2013. 246 с.

6. Краснощекова Г.А., Цатурова И.А. Факторы, оказывающие влияние на успешное овладение иностранным языком студентами технических вузов // Известия ЮФУ. Технические науки. 2013. № 10 (147). C. 58-63.

\section{DEVELOPMENT OF PROFESSIONAL FOREIGN LANGUAGE SPEAKING COMPETENCES OF STUDENTS MAJORING IN «TOURISM BUSINESS» AT THE ECONOMIC UNIVERSITY} (C) 2019

Glukhov Gennady Vasilyevich, doctor of pedagogical sciences, professor, head of Linguistics and Foreign Language Business Communication Department

Ermakova Yulia Dmitrievna, candidate of pedagogical sciences, associate professor of Linguistics and Foreign Language Business Communication Department Kapustina Lyubov Viktorovna, candidate of pedagogical sciences, associate professor of Linguistics and Foreign Language Business Communication Department Samara State University of Economics (Samara, Russian Federation)

Abstract. This paper discusses ways to optimize the process of students' professional foreign language competence development at a non-linguistic university, based on students' language and speech training at the economic university training program of «Tourism business», which combines a comprehensive business training with entrepreneurial approach to future qualified professionals working in the leisure and tourism industry. This involves acquisition of necessary competencies by students, aiming them at the prospect of becoming entrepreneurs and managers who are able to realize their working potential both at the national and international level. This, in turn, imposes quite high requirements for professional language training at a non-linguistic university and implies fluency in a foreign language by graduates. An additional catalyst for the Samara Region and a dozen other regions of the Russian Federation was the 2018 FIFA World Cup, which stimulated the formation of modern infrastructure of the tourism industry and confirmed relevant changes in the field of higher education. Globalization and the Internet have changed all aspects of foreign language training, including at a non-language university, especially for the tourism and hotel industry. Many of the strategies that have been applied in higher education until recently are no longer effective at present because of new and constantly evolving technical capabilities.

Keywords: professional language training; tourism business; students' professional foreign language competence development; effective strategies in mastering foreign language; English in field of professional communication; language and speech competence; non-linguistic university. 